\title{
ARE THERE DIFFERENCES IN THE DEVELOPMENT OF THE EXECUTIVE FUNCTIONS OF CHILDREN WITH A TYPICAL AND ATYPICAL DEVELOPMENT STIMULATED BY A GAME ON A TABLET?
}

\author{
Cristian A. Rojas-Barahona ${ }^{1}$, Carla E. Förster Marín ${ }^{2}$, Francisco Aboitiz ${ }^{3}$, \& Jorge Gaete ${ }^{4}$ \\ ${ }^{I}$ Faculty of Psychology/Faculty of Education Sciences, Research Center on Cognitive Sciences, \\ Universidad de Talca (Chile) \\ ${ }^{2}$ Vice-rectory of Undergraduate, Universidad de Talca (Chile) \\ ${ }^{3}$ Faculty of Medicine, Pontificia Universidad Católica de Chile (Chile) \\ ${ }^{4}$ Faculty of Education, Universidad de los Andes (Chile)
}

\begin{abstract}
Introduction: Executive functions (EF) are developed early, building a fundamental basis of higher cognitive processes in adulthood (Garon et al., 2008). There are studies with children of typical development (Passolunghi et al., 2006; Welsh et al., 2010) that have demonstrated the key role of EF, such as working memory, inhibitory control, planning and attentional flexibility, in initial literacy and precalculus. What is still unclear is whether these EF can be stimulated early and if it has any effect on their development. At the same time, it is known that children with atypical development, such as ADHD, have deficiencies in the development of EF (Barkley, 1997). Early stimulation of EF in this type of population will have the same effects as in a typical development population? The objective of the study is to evaluate the effect of a stimulation program of the EF (working memory, inhibitory control, planning and attentional flexibility), by means of a tablet digital game, in the development of the EF of preschool children with and without symptoms of ADHD, of socioeconomically disadvantaged sectors. Method: Two groups, control (CG) and intervention (IG) were selected at random, both were evaluated twice (before and after). In total there were 408 participants, 212 with typical development and 196 with atypical development. The IG was exposed to a digital game of EF through a tablet during 12 sessions (in the classroom). Results: The main results show differences in favor of IG in the different EF evaluated, both for children with and without ADHD symptoms, with the exception of attentional variable for which no differences were observed. There are differences in the effect of EF among children evaluated. Discussion: These differences and their possible implications in the educational and social environment are discussed.
\end{abstract}

Keywords: Early stimulation, executive functions, typical/atypical development.

\section{Introduction}

The basis for Executive functions (EF) are developed during preschool age, being this, essential for highly cognitive processes development during adulthood (Garon, Bryson \& Smith, 2008).

There are many EF definitions, and some common aspects between them. For example, EF are a set of skills that allow children regulate themselves, plan, monitor and evaluate their performance in solving a problem (Zelazo, Muller, Frye, y Marcovitch, 2003), and also, contribute to adaptability, generate goal-directed behaviors, and block their thoughts and automatic answers (Mesulam, 2002). In other words, it is understood that EF are an integrated construction by different skills (although there is no agreement about the constitutive skills) that directs behavior, as: response inhibition, working memory, attentional flexibility (for example, Zelazo, Carter, Reznick, \& Frye, 1997), planification, cognitive flexibility (for example, Denckla, 1996), among other skills. Barata (2011), in a 4 years old children's study, confirmed the unity of EF's different skills and, at the same time, the great diversity of them in the studied population.

Tominey and McClelland (2013) raise three reasons to work on EF stimulation since prekindergarten (especially self-regulation skills associated): a) this is the $1^{\text {st }}$ formal class environment where children are asked to demonstrate self-regulatory behaviors (read McClelland \& Cameron, 2012); during these years important prefrontal cortex changes happen related with its maturation. This area is associated with executive aspects development which can be improved with practice; and c) the EF development level predicts a better academic performance. Since ADHD study, 4 years old is considered a good development moment to work on EF because it is before many chronic comorbidities, 
deteriorating and related characteristics emerge that give rise to a worst long-term prognosis (Sonuga-Barke \& Halperin, 2010). Also, psychostimulants are still potentially controversial for preschoolers and look less effective in this age group (Kollins \& Greenhill, 2006) and secondary effects could be less common (Wigal et al., 2006).

Last 20 years, evidence that proves EF can be stimulated in children with typical development has been increased (for example, Duncan et al., 2007; Rojas-Barahona et al., 2015) and in children with atypical development, like ADHD symptoms (for example, Klingberg et al., 2002). In these experiences Cogmed Working Memory Training (Klingberg et al., 2002) is an outstanding program that stimulates working memory and is aimed at children with neurological lack of maturity as would-be ADHD diagnosed. The stimulation working memory program consists in 20-25 sessions, adjusting the level of difficulty of each task according to each child's performance. Its positive effect has been informed both in typical development children (Thorell et al., 2009) and in children with ADHD (Beck et al., 2010). In general, there is evidence that proves stimulation cognitive programs bring short- and long-term benefits. In this way, research findings by Burger (2010) show positive effects in most programs about cognitive development, measured in different researches by academic performance tests, level of instruction, or years of schooling, also, they verify other studies results that have established preschool programs used to present positive significant short and middle term effects in cognitive and socio-affective children development (for example, Anderson et al., 2003; Barnett, 1995; Reynolds et al., 2007). Even so, as all advancement of knowledge have been differences in the methodological approach (Willoughby, Wirth $y$ Blair, 2012), so is highly recommended to take evidence with prudence.

However, there are limited program experiences which stimulate many EF in preschoolers, including working memory, inhibitory control, attentional flexibility, planning, with typical and atypical development population, because those EF are essential not only in typical development children, but also in atypical development children, as it would be in ADHD symptom children. This takes more emphasis if it is placed on least advantaged communities in socio economic terms, because there is evidence that this group of people have less EF development in early development (for example, Neuenschwander et al., 2009; Wanless et al., 2011).

\section{Objective}

This study has as objective evaluate the effect of EF stimulation program (working memory, inhibitory control, planning and attentional flexibility), by means of a digital tablet game, in the development of the EF of preschoolers with and without ADHD symptoms, of socioeconomically disadvantaged sectors.

\section{Methods}

\subsection{Design}

An experimental Comparative and Explanatory Study design was used, where independent variables explicative capacity is established: executive functions (4 EF) stimulation program and ADHD symptoms (with and without symptoms); about dependent variables (working memory, inhibitory control, attentional flexibility and planning). Design was $2 \times 2$ with 1 intervention group (IG: stimulating working memory game, inhibitory control, attentional flexibility and planning), and 1 control group (CG: without intervention), and 2 groups of children (G1: children without ADHD symptoms; G2: children with ADHD symptoms). Two measures were made for this research, the first one before intervention (T1), and the second one just after the intervention (T2). Groups were conformed randomly.

\subsection{Participants}

408 boys (171) and girls (237) participated: 212 with typical development $(\mathrm{IG}=72 ; \mathrm{CG}=54)$ and 196 with atypical development with ADHD symptoms $(\mathrm{IG}=124 ; \mathrm{CG}=158)$. The average age was 51 month and 2 days (s.d. 6.70), all the boys and girls were pre kindergarteners in public schools in the Metropolitan Region of Chile. All of those schools have a vulnerability index higher than $75 \%$ according to MINEDUC-Chile statistics. When schools were randomly elected, principals, teachers, parents, and families received an informed consent. And before application all children were asked for their assent verbally. Then, a screening was done with all children in order to detect ADHD symptoms. Research had the approval by the Pontifical Catholic University of Chile's ethics committee.

\subsection{Procedure}

3.3.1. Groups description. Intervention Group (IG): intervention was by a digital game program that stimulated working memory, inhibitory control, attentional flexibility and planning, in a single way, during 12 sessions of 30 minutes, twice per week. Control Group (CG): during 12 sessions of 30 minutes, 
twice per week, played a digital game that didn't mean cognitive stimulation. By the end of the activity, children of both groups knew their own score and received a sticker for their participation. Every participant was evaluated individually in 2 different moments: one after intervention, at the beginning of the school year, and the other one at the end of the intervention asking them to use a focalized task in working memory, inhibitory control, planning, and attentional flexibility, in sessions of 25 minutes approximately each. In total, 2 sessions were needed to evaluate each moment per child. Tasks were applied at the student's own schools, in a quiet room.

3.3.2. Principles of intervention. For the interventions in preschoolers, interventional program is based on Dehn's (2008) proposal: a) degree of difficulty: increases difficulty; b) recurrence practices: training trials; c) strategies rotation: every sessions were designed ensuring that strategies change, with the same duration each; d) variety of activities: each session consists in 8 different activities; e) Short duration: activities were designed in order to be solved quickly; f) achievement: this program was designed in order to children could achieve a successful performance in their first trials.

3.3.3. Measuring EF instruments. These tests were chosen because they are adapted for the Chilean population and also, they had good psychometric indices (Cronbach's alpha higher than 0,8). A) working memory: short Spanish version was used (Injoque-Ricle, Calero, Alloway, \& Burin, 2011) Automated Working Memory Assessment (AWMA, Alloway, 2007) was the author; b) Planning: Tower of London test was used (TOL) (Shallice, 1982); c) Inhibitory control: Head-Toes-Knees-Shoulders (HTKS) de McClelland \& Cameron, 2012) was implemented; d) Attentional flexibility (executive): Attentional Network Test (ANT) de Fan et al. (2002) was used. Also, Conners 3 was used for screening. And attendance and performance register after each session was part of the fidelity of implementation.

3.3.4. Information analysis plan. Descriptive statistics analysis was done in order to find characteristics of each group. To respond to the objective, following data analysis were done: ANOVA to compare the beginning results with the effects of interaction, and ANCOVA, controlled by the $1^{\text {st }}$ measurement results.

\section{Results}

The initial evaluation only shows differences between children with and without symptoms in planning and in inhibitory control. The $2^{\text {nd }}$ evaluation, ANCOVA results show significant differences between IG and CG $(\mathrm{p}<, 001)$ after controlling the pretest effect in WM, inhibitory control, and planning (see table 1). These differences are in favor of IG for the 3 variables. Attentional flexibility doesn't show differences between groups nor interaction effects.

There is an interaction effect for the WM case $(\mathrm{F}(1 ; 407)=23,702 ; \mathrm{p}<0,001)$, it shows a significant lower progress for the group with ADHD symptoms compared with other 3 groups, while the IG with symptoms doesn't shows differences with other groups without symptoms. In planning, there is an interaction effect too $(\mathrm{F}(1 ; 407)=9,473 ; \mathrm{p}<0,05)$, similar with WM.

Table 1. Descriptive statistics and comparative values of study variables in the pre-test and post-test.

\begin{tabular}{|c|c|c|c|c|c|c|c|c|c|c|c|c|c|}
\hline & & \multicolumn{4}{|c|}{ Pre-test } & \multicolumn{4}{|c|}{ Post-test } & \multicolumn{4}{|c|}{$\mathrm{T} 2$ comparison controlled by $\mathrm{T} 1$} \\
\hline Executive function & Group & \multicolumn{2}{|c|}{ With ADHD } & \multicolumn{2}{|c|}{$\begin{array}{l}\text { Without } \\
\text { ADHD }\end{array}$} & \multicolumn{2}{|c|}{ With ADHD } & \multicolumn{2}{|c|}{$\begin{array}{l}\text { Without } \\
\text { ADHD }\end{array}$} & \multicolumn{2}{|c|}{ IG-CG } & \multicolumn{2}{|c|}{$\begin{array}{c}\text { ADHD } \\
\text { condition }\end{array}$} \\
\hline \multirow{3}{*}{ Working memory } & Comparison & 29,83 & 17,69 & 36,41 & 18,87 & 33,12 & 26,62 & 56,47 & 16,82 & \multirow{3}{*}{45,211} & \multirow{3}{*}{, $000 * *$} & \multirow{3}{*}{18,437} & \multirow{3}{*}{, $000 * *$} \\
\hline & Intervention & 35,68 & 21,70 & 34,60 & 15,54 & 62,17 & 22,42 & 60,56 & 22,12 & & & & \\
\hline & Total & 33,52 & 20,47 & 35,06 & 16,43 & 51,50 & 27,79 & 59,52 & 20,94 & & & & \\
\hline \multirow[t]{2}{*}{ Planning } & Intervention & 7,29 & 6,72 & 8,03 & 6,38 & 13,82 & 8,26 & 15,24 & 7,98 & \multirow[t]{2}{*}{18,559} & \multirow[t]{2}{*}{, $000 * *$} & \multirow[t]{2}{*}{20,104} & \multirow[t]{2}{*}{, $000 * *$} \\
\hline & Total & 6,57 & 6,48 & 8,37 & 6,66 & 11,37 & 8,44 & 15,10 & 7,82 & & & & \\
\hline \multirow{2}{*}{$\begin{array}{l}\text { Attentional } \\
\text { flexibility }\end{array}$} & Comparison & 37,15 & 265,33 & 44,35 & 217,78 & 27,18 & 115,81 & 29,61 & 103,87 & \multirow[b]{2}{*}{0,122} & \multirow[b]{2}{*}{, 727} & \multirow[b]{2}{*}{, 031} & \multirow[b]{2}{*}{, 860} \\
\hline & Intervention & 21,55 & 244,10 & 39,18 & 210,64 & 31,51 & 114,39 & 34,43 & 146,11 & & & & \\
\hline Inhibitory control & Total & 10,08 & 13,15 & 13,60 & 14,66 & 23,96 & 18,01 & 31,37 & 16,55 & 23,476 &, $000 * *$ & 9,462 &, $002 * *$ \\
\hline
\end{tabular}


Inhibitory control doesn't show interaction effect $(\mathrm{F}(1 ; 407)=0,330 ; \mathrm{p}>0,05)$, and main differences are in the intervention received because with ADHD symptoms children as well as without symptoms obtain higher mean than CG.

\section{Discussion/conclusions}

Observed results confirm that the same early stimulation by a digital game on tablet has benefits on children with typical and atypical development on their different EF, particularly in the working memory, planning and inhibitory control. Attentional flexibility was not affected in either group. Reasons could be many, one of them is related to the difficulty of stimulation of this EF and it needs more stimulation time than other cognitive skills.

Another important element to consider, is the positive impact of the program in children with and without ADHD symptoms, nevertheless it can be observed that typical development children have a good EF development independent of their stimulation. This is not observed in atypical development children (with ADHD symptoms), where stimulation plays an important role for the EF development.

There are significant social and educational implications with these results because they allow us to confirm that it is possible to design programs for both groups and it is not necessary to divide them, even from an early age. Also, it looks relevant to stimulate atypical development children so that they can develop their cognitive skills such as EF.

\section{References}

Alloway, T.P. (2007). Automated Working Memory Assessment (AWMA). London, UK: Harcourt Assessment.

Anderson, LM, Shinn, C, Fullilove, MT, Scrimshaw, SC, Fielding, JE, Normand J. (2003). The effectiveness of early childhood development programs. American Journal of Preventive Medicine, $24,32-46$.

Barata, M.C. (2011). Executive Function Skills in Chilean Preschool Children. Doctoral dissertation unpublished, Harvard University, Cambridge, Massachusetts, USA

Barkley, R.A. (1997). Behavioral inhibition, sustained attention, and executive functions: Constructing unifying theory of ADHD. Psychological Bulletin, 121, 65-94

Barnett, WS (2005). Long-term effects of early childhood programs on cognitive and school outcomes. The Future of Children, 5 (3), 25-50.

Beck, S. J., Hanson, C. A., Puffenberger, S. S., Benninger, K. L., \& Benninger, W. B. (2010). A controlled trial of working memory training for children and adolescents with ADHD. Journal of Clinical Child \& Adolescent Psychology, 39, 825-836.

Burger K. (2010). How does early childhood care and education affect cognitive development? An international review of the effects of early interventions for children from different social backgrounds. Early Childhood Research Quarterly, 25(2), 140-65.

Dehn, M.J. (2008). Working Memory and Academic Learning. Assessment and Intervention. New Jersey, USA: John Wiley \& Sons.

Denckla, M. B. (1996). A theory and model of executive function: a neuropsychological perspective. In G. R. Lyon \& N. A. Krasnegor (Eds.), Attention, memory, and executive function (pp. 263-278). Baltimore, MD: Paul H. Brookes.

Duncan, G. J., Dowsett, C. J., Claessens, A., Magnuson, K., Huston, A.C., \& Klebanov, P. (2007). School readiness and later achievement. Developmental Psychology, 43(6), 1428-1446. doi:10.1037/0012-1649.43.6.1428

Fan, J., McCandliss, B.D., Sommer, T., Raz, M. \& Posner, M.I. (2002) Testing the Efficiency and Independence of Attentional Networks. Journal of CognitiveNeuroscience, 14, 340-347.

Garon, N., Bryson, S., \& Smith, I.M. (2008). Executive Function in Preschoolers: A Review Using an Integrative Framework. Psychological Bulletin, 134(1), 31-60. doi: 10.1037/0033-2909.134.1.31

Injoque-Ricle, I., Calero, A.D., Alloway, T.P., \& Burin, D.I. (2011). Assessing working memory in Spanish-speaking children: Automated Working Memory Assessment battery adaptation. Learning and Individual Differences, 21(1), 78-84. doi: http://dx.doi.org/10.1016/j.lindif.2010.09.012

Klingberg T, Forssberg H, \& Westerberg H (2002). Training of working memory in children with ADHD. J Clin Exp Neuropsychol, 24, 781-791.

Kollins, S. H., \& Greenhill, L. (2006). Evidence bases for the use of stimulant medication in preschool children with ADHD. Infants \& Young Children, 19, 132-141. Merrell, K., Ervin, R. A., \& Gimpel, G. (2006). School Psychology for the 21st century. New York: Guilford. 
McClelland, M.M., \& Cameron, C. (2012). Self-regulation in early childhood: Improving conceptual clarity and developing ecologically-valid measures. Child Development Perspectives, 6(2), 136-142. doi:10.1111=j.1750-8606.2011.00191.x

Mesulam, M. M. (2002). The human frontal lobes: Transcending the default mode through contingent encoding. In D. T. Stuss \& R. T. Knight (Eds.), Principles of Frontal Lobe Function (pp. 8-30). New York: Oxford University Press

Neuenschwander, R., Röthlisberger, M., Michel, E., \& Roebers, C.M. (2009). Influence of socioeconomic status on executive functions among kindergarten children. Poster presented at the biennial meeting of the Society for Research in Child Development, Denver, CO.

Passolunghi, M.C., Vercelloni, B., \& Schadee, H. (2006). The precursors of mathematics learning: Working memory, phonological ability and numerical competence. Cognitive Development, 22, $165-184$. doi: 10.1016/j.cogdev.2006.09.001

Reynolds, AJ, Temple, JA, Ou, SR, Robertson, DL, Mersky, JP, \& Topitzes JW. (2007). Effects of a school-based, early childhood intervention on adult health and well-being. Archives of Pediatrics \& Adolescent Medicine, 161 (8), 730-739.

Rojas-Barahona, C. A., Förster Marín, C. E., Moreno-Ríos, S., \& McClelland, M. M. (2015). Improvement of Working Memory in Preschoolers and Its Impact on Early Literacy Skills: A Study in Deprived Communities of Rural and Urban Areas. Early Education \& Development, 26(5-6), 871-892. doi: http://dx.doi.org/10.1080/10409289.2015.1036346.

Shallice, T. (1982). Specific impairments of planning. Philosophical Transcripts of the Royal Society of London, 298(2), 199-209.

Sonuga-Barke; E., \& Halperin, JM. (2010). Developmental phenotypes and causal pathways in attention deficit/hyperactivity disorder: potential targets for early intervention? J Child Psychol Psychiatry, 51(4), 368-89.

Thorell, L. B., Lindqvist, S., Bergman, S., Bohlin, G., \& Klingberg, T. (2009). Training and transfer effects of executive functions in preschool children. Developmental Science, 12, 106-113.

Tominey, S.L., \& McClelland, M.M. (2013). Red light, purple light: Findings from a randomized trial using circle time games to improve behavioral self-regulation in preschool. In M.M. McClelland and S.L. Tominey (Eds.), Self-regulation and Early school success (pp. 135-165). London, UK: Routledge.

Wanless, S.B., McClelland, M.M., Tominey, S.L., \& Acock, A.C. (2011). The Influence of Demographic Risk Factors on Children's Behavioral Regulation in Prekindergarten and Kindergarten. Early Education \& Development, 22(3), 461-488. doi: 10.1080/10409289.2011.536132

Welsh, J.A., Nix, R.L., Blair, C., Bierman, K.L., \& Nelson, K.E. (2010). The Development of Cognitive Skills and Gains in Academic School Readiness for Children from Low-Income Families. Journal of Educational Psychology, 102 (1), 43-53. doi: 10.1037/a0016738

Wigal SB., Wigal TL., \& Kollins SH. (2006) Advances in methylphenidate drug delivery systems for ADHD therapy. Adv ADHD, 1, 4-7.

Willoughby, M.T., Wirth, R. J., \& Blair, C. B. (2012). Executive function in early childhood: longitudinal measurement invariance and developmental change. Psychol Assess, 24(2), 418-431.

Zelazo, P. D., Carter, A., Reznick, J. S., \& Frye, D. (1997). Early development of executive function: A problem-solving framework. Review of General Psychology, 1, 198-226.

Zelazo, P. D., Muller, U., Frye, D., \& Marcovitch, S. (2003). The development of executive function in early childhood. Monographs of the Society for Research in Child Development, 68(3), Serial No. 274. 